\title{
Behaviours and attitudes related to smoking among a Bedouin population in rural Jordan
}

\author{
J. Eggert ${ }^{7}$ and W.K. Al-Delaimy
}

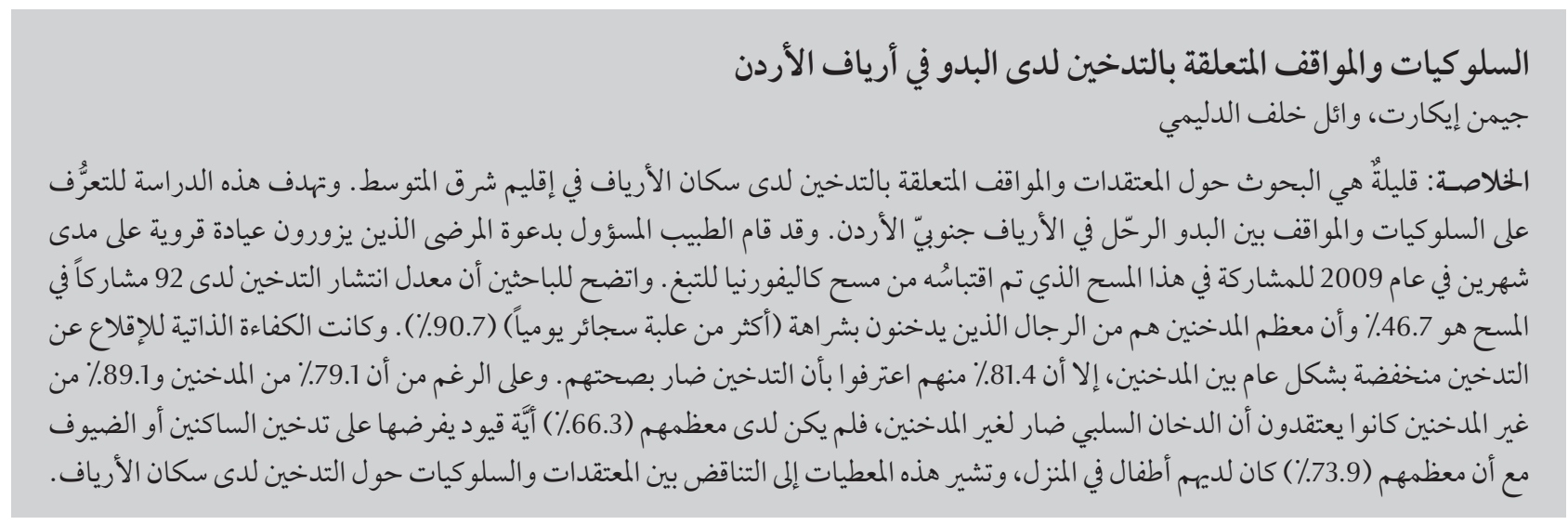

ABSTRACT There is limited research about tobacco-related behaviours and attitudes among rural populations in the Eastern Mediterranean Region. The aim of this study was to determine smoking behaviours and attitudes among the nomadic Bedouin in rural southern Jordan. Patients visiting a village clinic over 2 months of 2009 were invited by the attending physician to participate in the survey, which was adapted from the California Tobacco Survey. The smoking prevalence among the 92 participants was $46.7 \%$. Most smokers were men who smoked heavily (> 1 pack/day) (90.7\%). There was general low self-efficacy to quit among smokers, yet $81.4 \%$ acknowledged that smoking was harming their health. Although $79.1 \%$ of smokers and $89.1 \%$ of non-smokers believed second-hand smoke was harmful to non-smokers, most of them had no restrictions on smoking for residents and guests $(66.3 \%)$ and most had children at home (73.9\%). These data demonstrate contradictions between attitudes and behaviours about smoking of this rural population.

\section{Comportements et attitudes en matière de tabagisme dans une population bédouine en Jordanie rurale}

RÉSUMÉ Les travaux de recherche sur les comportements et les attitudes concernant le tabac sont limités dans les populations rurales de la Région de la Méditerranée orientale. La présente étude visait à déterminer les comportements et les attitudes en matière de tabagisme chez les Bédouins nomades du sud rural de la Jordanie. Pendant deux mois en 2009, les patients en consultation dans un centre de santé de village ont été invités par le médecin traitant à participer à l'étude, adaptée du California Tobacco Survey. La prévalence du tabagisme chez les 92 participants était de 46,7\%. La plupart des fumeurs $(90,7 \%)$ étaient des hommes ayant une forte consommation de tabac (> 1 paquet/jour). Le sentiment d'auto-efficacité pour le sevrage tabagique était généralement faible chez les fumeurs, tandis que 81,4 \% reconnaissaient que le tabagisme était nocif pour leur santé. Si 79,1\% des fumeurs et 89,1 \% des nonfumeurs étaient convaincus que le tabagisme passif était nocif pour les non-fumeurs, la majorité d'entre eux n'avait aucune restriction sur la consommation de tabac à leur domicile pour les membres du foyer comme pour les invités (66,3\%) alors que la plupart avaient des enfants à la maison (73,9\%). Ces données mettent en évidence des contradictions entre les attitudes et les comportements au sujet du tabagisme dans cette population rurale.

${ }^{1}$ Department of Family and Preventive Medicine, University of California, San Diego, California, United States of America (Correspondence to W. Al-Delaimy:waldelaimy@ucsd.edu).

Received: 01/03/12; accepted: 22/04/12 


\section{Introduction}

Research has led to a clear understanding of the many adverse health effects of smoking. Smoking tobacco reduces life expectancy and productivity and increases health care costs due to cardiovascular and respiratory diseases, cancers and other illnesses [1]. These risks are well documented and are not limited to smokers but also affect non-smokers, including children, who are passively exposed to second-hand smoke (SHS) $[2,3]$. As a result, the MPOWER guidelines based on the World Health Organization's (WHO) Framework on Tobacco Control (FCTC) were created to lower health risks related to smoking exposure by a series of 6 steps [4].

Smoking-related health education in Jordan began in 2001 when the Jordanian Ministry of Health launched a 3-month media campaign against tobacco use in the country. This expanded in the following 2 years as Jordan adopted the FCTC in May of 2003 $[5,6]$. These education programmes are designed to emphasize smoking risks for the population and the importance of tobacco control approaches. Review literature has discussed the effectiveness of these programmes; however, there are no evaluation studies of the effectiveness and reach of such programmes to rural areas and populations [7].

Previous studies have been conducted to understand smoking patterns in both urban and rural areas of the Eastern Mediterranean Region [8-13]. Smoking prevalence and behaviour in some rural populations, such as in Egypt and Saudi Arabia, have been identified from earlier studies (Table 1) [14-16].

This study was intended to describe the smoking prevalence among smokers in a rural community in Jordan, assess secondhand smoke exposure among non-smokers, understand how independent factors of age, sex and education impact exposure and understand local perceptions about tobacco smoke and its health consequences.

\section{Methods}

\section{Study setting and sample}

A cross-sectional, descriptive study was conducted in October and November 2009 at a local clinic near Quray'qira in the Faynan region of southern Jordan. The local population is mostly Bedouin and estimated to be between 2000 and 3000 individuals in the region. Bedouin populations live nomadically and therefore a complete survey of the population would be difficult. We utilized the main local clinic, with the help of the local Jordanian physician, to reach this dispersed population and provide culturally appropriate interaction and interviews with the participants.

All clinic patients and their relatives age 15 years and older were considered potential participants. An outside individual not familiar with the study aims selected the days of data collection on a weekly basis and sampling was conducted by invitation from the local physician. Locals from the region but outside the population served by the clinic were also eligible to participate. Therefore, to be eligible for this study, each participant needed to be a resident of the Faynan region. Out of 100 residents invited, 92 accepted to participate in the study (a 92\% response rate). Each participant orally consented to be included in the study and the study was approved by the University of California, San Diego Human Research Protection Program.

\section{Data collection}

The survey consisted of standardized questions adapted from the 2008 California Tobacco Survey (CTS) [17]. The CTS was written in English and was translated to Arabic by a Jordanian bilingual and verified by the author (W.A.D). English and Arabic versions of the survey were provided to the local Jordanian physicians who presented the survey questions to the participants.

Smokers were asked 27 questions and non-smokers were asked 11 questions, as well as additional demographic questions. Smokers were defined as those who currently smoked commercial cigarettes or rolled their own tobacco cigarettes. Additional questions to smokers investigated the use of a waterpipe (also known as hookah, nargila or shisha). Past and current smokers were asked about their age of smoking onset $(<10,10-14,15-20$, $>20$ years) and current smokers were asked about their smoking frequency (daily, biweekly, weekly, monthly) and intensity (number of cigarettes/day). Initial age of smoking onset and the time of the first daily cigarette smoked after waking were recorded. Smokers were also asked about their preferred forms of smoking, the impact of cost on their smoking habits and the effect of smoking on their income.

Non-smokers were asked questions to determine SHS exposure (yes/no), frequency of SHS exposure (no exposure, exposure with family member at home, exposure from guests), number of smokers in the house (family members or guests) and the frequency of the smokers' visits to the house (daily, 2 times a week, weekly, monthly).

All individuals were asked questions that reflected their opinions and behaviours regarding smoking and the health consequences to smokers and non-smokers. Opinion and behavioural questions had predetermined responses and the participant selected the response they identified the most with.

Individual responses to the questionnaire were verbally communicated by each participant and recorded by the survey administrator. Data from individual questionnaires were entered anonymously to ensure confidentiality and the hard copies were destroyed. 


\begin{tabular}{|c|c|c|c|c|}
\hline \multirow[t]{2}{*}{ Country } & \multirow[t]{2}{*}{ Year } & Prevalence & Males & Females \\
\hline & & $\%$ & $\%$ & $\%$ \\
\hline \multicolumn{5}{|l|}{ National surveys } \\
\hline Islamic Republic of Iran [25] & 2010 & 12.5 & 23.4 & 1.4 \\
\hline Iraq [3] & 2005 & 10.0 & 21.0 & 2.1 \\
\hline Jordan [6] & 2011 & 29.0 & - & - \\
\hline Kuwait [26] & 2000 & - & 34.4 & 19.0 \\
\hline \multicolumn{5}{|l|}{ Urban surveys } \\
\hline Egypt [27] & 2007 & 45.0 & $88.0^{\mathrm{a}}$ & $22.7^{\mathrm{a}}$ \\
\hline Jordan [24] & 2008 & 43.6 & - & - \\
\hline Jordan [28] & 2008 & 35.0 & 56.9 & 11.4 \\
\hline Jordan [29] & 2006 & - & 22.4 & 9.1 \\
\hline Syrian Arab Republic [30] & 2006 & - & 56.9 & 17.0 \\
\hline \multicolumn{5}{|l|}{ Rural surveys } \\
\hline Egypt [14] & 2009 & 18.4 & 18.3 & 0.1 \\
\hline Egypt [19] & 2003 & 7.7 & 11.5 & 0.0 \\
\hline Saudi Arabia [16] & 2003 & 15.0 & - & - \\
\hline Saudi Arabia [15] & 1995 & - & 17.0 & 0.0 \\
\hline
\end{tabular}

${ }^{a}$ When married

- = no data reported.

\section{Data analysis}

All data were recorded electronically on a Microsoft Excel database to tabulate responses. Descriptive statistical analyses were conducted using Stata statistical software according to the smoking status of participants.

\section{Results}

\section{Prevalence of smoking}

A total of 43 individuals (46.7\%) reported that they smoked, and 3 were ex-smokers. Although for the main purpose of this study smoking was defined as tobacco cigarettes, either purchased or rolled, the waterpipe was also smoked by $30.2 \%$ of the smokers. No other methods of smoking, legal or illegal substances were recorded.

Smokers were equally distributed across the 3 age groups (age $<24$ years, $25-40$ years and $>40$ years). A large majority of smokers were males (90.7\%), while $54.3 \%$ of the nonsmokers, were males (Table 2).

\section{Smokers' behaviours and attitudes}

Table 3 shows the behaviours and attitudes among smokers. A total of $39.6 \%$ of smokers began smoking in adolescence before the age of 15 years. As a measure of addiction, $41.9 \%$ of smokers reported that they smoked their first cigarette within 15 minutes of waking up. Furthermore, $46.5 \%$ of smokers said they never intended to quit smoking, and $48.8 \%$ were very unsure of their own ability to refrain from smoking.

Among the smokers, the perceived health impact on others was assessed: $74.4 \%$ of smokers acknowledged that tobacco smoke was harmful to the health of others, children and themselves (all 3 items), while $86.0 \%$ thought it was harmful to at least 1 of these categories. Still, most individuals identified as a smoker smoked heavily (mean of 21.6 cigarettes/day). Additionally most respondents $(66.3 \%)$ had no restrictions on smoking in the home ( $56.5 \%$ of non-smokers and $76.1 \%$ of smokers and former smokers) despite the presence of children in $73.9 \%$ of the homes. There was a contradiction with the majority agreeing that smoking causes cancer in a non-smoker but with only $21.7 \%$ of the population having a smoking ban in the home.

The role of the medical professional in smoking behaviours was assessed. A small proportion (21.7\%) of the 46 current and former smokers reported receiving encouragement from a medical professional to stop smoking and 9/10 (90\%) of those encouraged by their doctor to quit smoking had attempted to quit. However, none of the former smokers listed a medical professional as a reason influencing their decision to stop smoking or a reason influencing the quitting process.

\section{Non-smokers' and smokers' attitudes}

The attitudes towards smoking among both smokers and non-smokers are described in Table $4 ; 84.8 \%$ of the total group acknowledged that smoke from someone else's cigarettes can cause lung cancer in a non-smoker and 89.1\% 


\begin{tabular}{|c|c|c|c|c|c|c|}
\hline \multirow[t]{2}{*}{ Variable } & \multicolumn{2}{|c|}{$\begin{array}{c}\text { Smokers } \\
(n=43)\end{array}$} & \multicolumn{2}{|c|}{$\begin{array}{l}\text { Non-smokers } \\
\quad(n=46)\end{array}$} & \multicolumn{2}{|c|}{$\begin{array}{l}\text { Former smokers } \\
\qquad(n=3)\end{array}$} \\
\hline & No. & $\%$ & No. & $\%$ & No. & $\%$ \\
\hline \multicolumn{7}{|l|}{ Age (years) } \\
\hline $15-24$ & 14 & 32.6 & 15 & 32.6 & 0 & 0.0 \\
\hline $25-40$ & 15 & 34.9 & 22 & 47.8 & 1 & 33.3 \\
\hline$>41$ & 14 & 32.6 & 9 & 19.6 & 2 & 66.7 \\
\hline \multicolumn{7}{|l|}{ Sex } \\
\hline Male & 39 & 90.7 & 25 & 54.3 & 3 & 100.0 \\
\hline Female & 4 & 9.3 & 21 & 45.7 & 0 & 0.0 \\
\hline \multicolumn{7}{|l|}{ Education } \\
\hline Illiterate & 19 & 44.2 & 24 & 52.2 & 3 & 100.0 \\
\hline Some high-school education & 22 & 51.2 & 19 & 41.3 & 0 & 0.0 \\
\hline College & 2 & 4.7 & 3 & 6.5 & 0 & 0.0 \\
\hline
\end{tabular}

agreed that it harms the health of children and babies.

Both the illiterate participants (69.6\%) and those with partial or complete secondary education $(66.7 \%)$ had an understanding of the potential health risks of tobacco. Participants with a college education responded with a complete understanding of tobacco risks $100 \%$ of the time.

\section{Discussion}

This study demonstrated that smoking in rural Jordan is a public health problem because of high exposure to SHS and high rates of active smoking despite awareness by a large proportion of the study participants of the health consequences of tobacco use. Jordan, the WHO and international tobacco control experts need to take notice of this paradox when implementing the MPOWER guidelines as part of the FCTC agreements.

Almost half of these participants were active smokers. Furthermore, heavy and addicted smoking behaviour was reported, with smokers consuming more than a pack per day on average. These findings are comparable to results from 3 Jordanian urban publications (rural Jordanian data are lacking). A survey of Jordanian health workers in 2007 found a smoking prevalence of $41.5 \%$ for nurses and $43.6 \%$ for physicians [18], while a survey in 2005 found a smoking prevalence of $35.0 \%$ among Jordanian university students [3] and WHO reported the smoking prevalence for the Jordan population in 2007 was 29\% [6].

SHS exposure was also prevalent among this population and guests were usually welcome to smoke in a home, even if there were children present and parents were non-smokers. This is an important difference when compared with findings from the tobacco control literature from developed countries where the presence of young children in homes is one of the most important predictors of implementation of home smoking bans [17]. A large majority of these respondents acknowledged that smoking harmed the health of children but still exposed them to tobacco, which suggests that while Jordanian health education programmes may be reaching their intended targets there is no reciprocal change in behaviour [5]. This discrepancy may be related to cultural factors and a social norm that prevents asserting a ban at home. Offending a guest is very serious in Arab culture, which could explain the inability of non-smokers to make their homes smoke-free.
Findings in nearby rural communities within neighbouring countries also reflect strong primary and secondary exposure to cigarette and other tobacco smoke, but none had prevalence rates as high as rural Jordan. In 1995, 17\% of boys in secondary schools in rural Saudi Arabia reported current smoking [15]. A study of the Bedouin in Saudi Arabia found $15 \%$ were active smokers in 2003 [16]. A study of secondary-school student smoking in the Qualyobia governorate of Egypt published in December 2003 found $7.7 \%$ were current smokers [19]. A smoking prevalence of $18.3 \%$ was reported in a rural area of Egypt in 2009 [14].

In the Middle East, there are major sex differences in the reported prevalence of smoking: the study in rural Saudi Arabia focused only on young boys [15], in the Qualyobia study there were no female current smokers [19] and the rural Egyptian population-based survey focused only on men for analysis due to finding only $0.1 \%$ of women were smokers [14].

An interesting finding from this study is that smoking prevalence in the largely poorly educated Bedouin population was comparable to the prevalence among higher educated health care professionals [18]. Typically in developed countries such as the United States and 
Europe, low socioeconomic status and low income are related to higher smoking prevalence, but this was not the case in Jordan. Our results also showed that $80 \%$ of smokers were not advised by their physician to quit smoking. There are many reasons why a patient may not be educated about cessation programmes but one explanation could be the high proportion of physicians in Jordan who are smokers themselves [18]. To change the social norm and behaviour in Jordan, physicians and health care providers should be targeted for tobacco control programmes.

In the United States, high smoking prevalence has been reduced through multiple components of education, health policy, grass-roots efforts, media and other components as part of comprehensive tobacco control programmes. The population trends in smoking in the state of California, for example, showed a decrease in prevalence from $18.6 \%$ in 1990 to $11.6 \%$ in 2008 due to the comprehensive California tobacco control programme $[20,21]$. Using the California model of widely implemented tobacco control programmes could have similar effects in Jordan.

Education campaigns about tobacco and SHS do not seem to be a priority target of the tobacco control programme in Jordan based on the existing high level of understanding of the harmfulness of smoking among the population. The large majority of these rural Jordanian smokers and non-smokers were familiar with the harmfulness of active and passive smoking. This contrasts with China, which is also a party of the FCTC, in which a study showed a large majority (75\%) did not fully understand the harmfulness of active or passive smoking [22]. Throughout data collection for this study, the evidence of Jordan's anti-tobacco advertisement and education programme was clearly visible as brightly coloured and descriptive "no-smoking" signs hung in the health clinic. Patients' cigarette packets

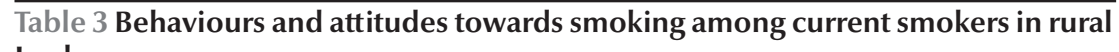

\section{Jordan}

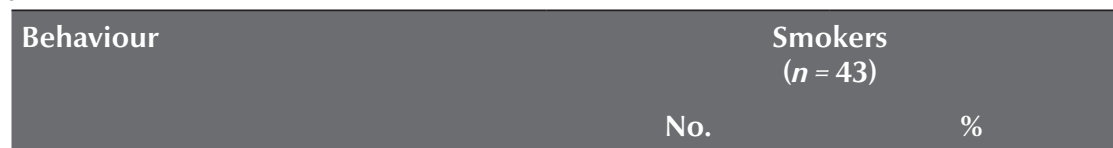

Age of starting smoking (years)

$<10$ 7.0

$10-14$

32.6

15-20

53.5

$>20$

7.0

Time of first cigarette each day

Immediately

27.9

$<15$ min.

14.0

15-60 min.

37.2

1-2 h

20.9

Smoking quit attempt in last year

Yes

46.5

No

Don't know/no opinion

Duration of quit attempt $(\boldsymbol{n}=20)$

$\begin{array}{lll}<1 \text { week } & 8 & 40.0 \\ <1 \text { month } & 9 & 45.0 \\ 1-6 \text { months } & 3 & 15.0\end{array}$

Ever smoked a waterpipe

Yes

No

Don't know/no opinion

Attitudes

\section{Able to refrain from smoking}

Very sure

30.2

Somewhat

18.6

Very unsure

48.8

Don't know

\section{Intention to quit}

Never expect to quit $\quad 20$

Not in next 6 months

32.6

In the next 6 months

16.3

Next month

My smoking is harming my health

Agree

81.4

Disagree

18.6

Don't know/no opinion

0.0

My smoking causes cancer in a nonsmoker

Agree

79.1

Disagree

16.3

Don't know/no opinion
4.7 


\begin{tabular}{|c|c|c|c|c|c|c|c|c|}
\hline \multirow[t]{2}{*}{ Attdude } & \multicolumn{2}{|c|}{$\begin{array}{l}\text { Total } \\
(n=92)\end{array}$} & \multicolumn{2}{|c|}{$\begin{array}{l}\text { Smokers } \\
(n=43)\end{array}$} & \multicolumn{2}{|c|}{$\begin{array}{l}\text { Non-smokers } \\
\quad(n=46)\end{array}$} & \multicolumn{2}{|c|}{$\begin{array}{l}\text { Former smokers } \\
\qquad(n=3)\end{array}$} \\
\hline & No. & $\%$ & No. & $\%$ & No. & $\%$ & No. & $\%$ \\
\hline \multicolumn{9}{|c|}{$\begin{array}{l}\text { Non-smokers are entitled to breathe air } \\
\text { free of tobacco smoke }\end{array}$} \\
\hline Agree & 76 & 82.6 & 35 & 81.4 & 38 & 82.6 & 3 & 100.0 \\
\hline Disagree & 9 & 9.8 & 3 & 7.0 & 6 & 13.0 & 0 & 0.0 \\
\hline Don't know/no opinion & 7 & 7.6 & 5 & 11.6 & 2 & 4.3 & 0 & 0.0 \\
\hline \multicolumn{9}{|c|}{$\begin{array}{l}\text { Inhaling smoke from someone else's } \\
\text { cigarette can cause lung cancer in a non- } \\
\text { smoker }\end{array}$} \\
\hline Agree & 78 & 84.8 & 34 & 79.1 & 41 & 89.1 & 3 & 100.0 \\
\hline Disagree & 9 & 9.8 & 7 & 16.3 & 2 & 4.3 & 0 & 0.0 \\
\hline Don't know/no opinion & 5 & 5.4 & 2 & 4.7 & 3 & 6.5 & 0 & 0.0 \\
\hline \multicolumn{9}{|c|}{$\begin{array}{l}\text { Inhaling smoke from someone else's } \\
\text { cigarette harms the health of babies and } \\
\text { children }\end{array}$} \\
\hline Agree & 82 & 89.1 & 34 & 79.1 & 45 & 97.8 & 3 & 100.0 \\
\hline Disagree & 4 & 4.3 & 4 & 9.3 & 0 & 0.0 & 0 & 0.0 \\
\hline Don't know/no opinion & 6 & 6.5 & 5 & 11.6 & 1 & 2.2 & 0 & 0.0 \\
\hline \multicolumn{9}{|c|}{ My family would prefer I didn't smoke } \\
\hline Agree & - & - & 40 & 93.0 & - & - & - & - \\
\hline Disagree & - & - & 3 & 7.0 & - & - & - & - \\
\hline Don't know/no opinion & - & - & 0 & 0.0 & - & - & - & - \\
\hline \multicolumn{9}{|c|}{ I tend to avoid socializing with smokers } \\
\hline Agree & - & - & - & - & 34 & 73.9 & 2 & 66.7 \\
\hline Disagree & - & - & - & - & 11 & 23.9 & 0 & 0.0 \\
\hline Don't know/no opinion & - & - & - & - & 1 & 2.2 & 1 & 33.3 \\
\hline
\end{tabular}

- = not applicable.

were covered with graphic pictures of smoking-related diseased tissues and health and safety warnings $[5,18]$. Jordan is recognized by the MPOWER monitoring programme as being one of 86 countries that implements at least one of the MPOWER policies [23]. Despite these recognized efforts to minimize the effects of smoking-related diseases, people in rural communities are smoking at record high levels compared with rural populations in nearby countries.

A critique of the countries that ratify the FCTC is their lack of enforcement of MPOWER policies. Jordan is one of these countries that signed the FCTC in its earliest phase in 2003, but more than 8 years since that event there has been little progress in implementing the requirements of the agreement through MPOWER. A ban on smoking on public places started in 2009 in Jordan but is not enforced in shopping centres or public buildings, due primarily to the lack of committed resources and the government's weak political will to implement these policies. Jordan, like many developing countries, does not have national infrastructure or resources to "effectively implement the necessary measures" [24]. In Jordan there are also cultural limitations that will need to be explored further. MPOWERstructured education programmes may be supplying the adequate information but are not tailored to the Bedouin.

This study was limited by recruiting from one Bedouin community and therefore we cannot claim that it is representative of a wider group. However, there is no reason to believe that behaviours of other Bedouin communities would be substantially different from our study population. This was a cross-sectional, descriptive study and therefore no associations were addressed. As with all questionnaire-based studies, the data were subjective and responses might have underestimated the true smoking and exposure prevalence among this population. We were not able to collect biomarker data because of culturally held beliefs against giving out samples. Hair or nail nicotine biomarker research in the future will improve the accuracy by objectively quantifying smoking exposure.

In conclusion, this study from a rural Bedouin area of Jordan demonstrated 
contradictions between beliefs and actual behaviours about smoking of this rural population. Although knowledge about the risks of tobacco smoke were good, suggesting that tobacco education programmes in Jordan may have been successful in raising awareness, children were still being exposed to SHS and smokers were not attempting to quit smoking or lower their cigarette consumption levels. Future studies need to understand the discrepancy between high levels of education about the harm of tobacco and low levels of behavioural change to limit harm to smokers and non-smokers. This would help promote better tobacco control programmes for such populations and has implications for other communities as well.

\section{Acknowledgements}

The authors acknowledge Professor Thomas Levy and the UC San Diego Edom Lowlands RegionalArchaeology
Project in Jordan and the Bedouin tribes of the Faynan region for making the study possible. Also thanks to Dr Bashar Mohammad Al-A'Amar and Dr Omar and their staff for their cooperation and support in the conduct of this study. Thanks as well to Jesse Wooton, and Caitlin Connolly for their effort in local contextualization of the survey questionnaires.

Funding: No outside sources.

Competing interests: None declared.

\section{References}

1. The health consequences of smoking: A report of the Surgeon General. Atlanta, Georgia, Centers for Disease Control and Prevention, 2004.

2. Gidding SS, Schydlower M. Active and passive tobacco exposure: a serious pediatric health problem. Pediatrics, 1994, 94:750-751.

3. Centers for Disease Control and Prevention. Tobacco use among students aged 13-15 years-Kurdistan region, Iraq, 2005. Morbidity and Mortality Weekly Report, 2006, 55:556-559.

4. Kaleta D, Koziel A, Miskiewicz P. [MPOWER-strategy for fighting the global tobacco epidemic]. Medycyna Pracy, 2009, 60:145-149 [in Polish].

5. Ma'ayeh SP. Jordan: mass media campaign combating smoking requires serious commitment and not just words. Geneva, World Health Organization, 2003 (http://www.who.int/tobacco/ training/success_stories/en/best_practices_jordan_media. pdf, accessed 20 March 2013).

6. Country profiles: Jordan. World Health Organization [online factsheet]. (http://www.emro.who.int/countries/jor/ accessed 20 March 2013).

7. Belbeisi A et al. A surveillance summary of smoking and review of tobacco control in Jordan. Globalization and Health, 2009, 5:18.

8. Benamer HT, Grosset D. Stroke in Arab countries: a systematic literature review. Journal of the Neurological Sciences, 2009, 284:18-23

9. Badran E, Salhab AS, Al-Jaghbir M. Infant exposure to environmental tobacco smoke: Jordan university hospital-based study. Eastern Mediterranean Health Journal, 2009, 15:39-46.

10. Dar-Odeh NS, Abu-Hammad OA. Narghile smoking and its adverse health consequences: a literature review. British Dental Journal, 2009, 206:571-573.

11. Khader A et al. Tobacco use among Palestine refugee students (UNRWA) aged 13-15. Preventive Medicine, 2009, 49:224-228.

12. Gad RR et al. Nicotine dependence among adult male smokers in rural Egypt. Journal of the Egyptian Society of Parasitology, 2003, 33(Suppl.):1019-1030.

13. Al-Damegh SA et al. Cigarette smoking behavior among male secondary school students in the central region of Saudi Arabia. Saudi Medical Journal, 2004, 25:215-219.

14. Boulos DN et al. Nondaily, light daily, and moderate-to-heavy cigarette smokers in a rural area of Egypt: a population-based survey. Nicotine and Tobacco Research, 2009, 11:134-138.

15. Al-Faris EA. Smoking habits of secondary school boys in rural Riyadh. Public Health, 1995, 109:47-55.

16. Almas $\mathrm{K}$ et al. Oral hygiene, dietary pattern and smoking habits of Bedouin (nomadic Arabs) population in
Saudi Arabia. Odonto-Stomatologie Tropicale, 2003, 26:19-23.

17. Al-Delaimy WK et al. Two decades of the California tobacco control program. California tobacco survey, 1990-2008. Sacramento, California, California Department of Public Health, 2010.

18. Shishani K, Nawafleh H, Sivarajan Froelicher E. Jordanian nurses' and physicians' learning needs for promoting smoking cessation. Progress in Cardiovascular Nursing, 2008, 23:79-83.

19. Gadalla $S$ et al. Prevalence of smoking among rural secondary school students in Qualyobia governorate. Journal of the Egyptian Society of Parasitology, 2003, 33(Suppl.):1031-1050.

20. Al-Delaimy WK et al. The California tobacco control program. Can we maintain the progress? La Jolla, California, University of California, San Diego, 2008

21. Al-Delaimy WK et al. The California tobacco control program's effect on adult smokers: (2) daily cigarette consumption levels. Tobacco Control, 2007, 16:91-95

22. Yang GH et al. Findings from 2010 global adult tobacco survey: Implementation of MPOWER policy in China. Biomedical and Environmental Sciences, 2010, 23:422-429.

23. The tobacco atlas-MPOWER [online] http://www.tobaccoatlas.org, accessed 20 March 2013).

24. Wipfli H, Samet JM. Global economic and health benefits of tobacco control: part 2. Clinical Pharmacology and Therapeutics, 2009, 86:272-280.

25. Meysamie A et al. Pattern of tobacco use among the Iranian adult population: results of the national survey of risk factors of non-communicable diseases (SuRFNCD-2007). Tobacco Control, 2010, 19:125-128.

26. Memon A et al. Epidemiology of smoking among Kuwaiti adults: prevalence, characteristics, and attitudes. Bulletin of the World Health Organization, 2000, 78:1306-1315.

27. Sabra AA. Smoking attitudes, behaviours and risk perceptions among primary health care personnel in urban family medicine centers in Alexandria. Journal of the Egyptian Public Health Association, 2007, 82:43-64.

28. Khader YS, Alsadi AA. Smoking habits among university students in Jordan: prevalence and associated factors. Eastern Mediterranean Health Journal, 2008, 14:897-904.

29. Merrill RM et al. Smoking prevalence, attitudes, and perceived smoking prevention and control responsibilities and behaviors among physicians in Jordan. International Quarterly of Community Health Education, 2006-2007, 26(4):397-413.

30. Ward KD et al. The tobacco epidemic in Syria. Tobacco Control, 2006, 15(Suppl. 1):i24-i29. 